\title{
The significance of a pandemic in teaching foreign languages, with special regard to the teaching of seniors
}

\author{
Aleksander Kobylarek - Emilia Alaverdov - Luba Jakubowska
}

\author{
DOI: 10.18355/XL.2021.14.01.06
}

\begin{abstract}
This article presents the results of research into the influence of a pandemic on education in the field of foreign languages. Research regarding opinions was conducted by the free interview technique on specially selected foreign language teachers in Poland, Belarus, Italy, Ukraine and Georgia. The areas researched covered opinions on various topics - changes in the functioning of educational institutions; changes in students' needs, expectations and behaviour, with special regard to seniors; problems connected with remote learning; changes in educational methods and content; and the specifics of teaching seniors foreign languages during a pandemic. As a result of qualitative analysis, three categories of problem emerged - pedagogical, didactic, and those specific to the teaching of seniors.
\end{abstract}

Key words: remote learning, Covid-19, language learning, education of seniors

\section{Introduction}

The explosion of the Covid-19 pandemic in 2019, together with its relatively swift proliferation in the months following, left the whole world in a singular situation (Daniel, 2020: 91-96). At first the virus was a fatal threat to those who were weak, old, and ill, especially those suffering from chronic diseases. However, after some time it turned out that in effect our whole species is under threat, and the complications among those who had survived the disease could last for a very long time and be the cause of serious long-term health problems. The threat to life and the possibility of long-term complications forced the authorities in various countries to adopt drastic counter-measures, such as the necessity of disinfecting hands, covering the respiratory tract or social distancing, ending in the suspension of the activities of institutions and shutting down whole areas of the economy, such as transport, trade, gastronomy and education (Murgas, Petrovic, 2020). Countries which more or less consciously ignored the facts (such as the United Kingdom and Sweden) in time paid with an increased death-rate among seniors and a sharp rise in infections.

The pandemic has had a direct and indirect influence on the education system (Biana, Joaquin, Dacela, 2020). For education, efforts to prevent the spread of the Covid-19 virus led to learning via the Internet. The limiting of contacts or social isolation connected with this must have had an effect on the methods of education, including foreign language teaching, as well as on educational content (Coskun, 2020; Bianco, Cobo, 2019ab). On the other hand, the education system fell victim to the problems in other economic sectors which we depend on, including those arising from defective government policies, household economic problems, personal uncertainty and danger (Flores, Swennen, 2020; Haskova, Manduliakova, Van Merode, 2017).

Direct contact during the teaching of languages has a huge significance (see: Szalma, Rekai, 2020). To some degree the teaching of foreign languages should be treated as a workshop, many of the elements of which cannot be replaced by remote learning (Biana, Joaquin, 2020b). A similar problem occurs in other cases such as professional education, physical education and theatre workshops. The unmediated presence of a teacher appears to be key when it comes to correcting mistakes swiftly or effective control of the learning process. (Gadusova, Haskova, Szarsoi, 2020). Apart from this, if we accept that the teaching process itself is a kind of communicative process, then it

XLinguae, Volume 14 Issue 1, January 2021, ISSN 1337-8384, eISSN 2453-711X 
can only be realized to the full by the unmediated presence of another (Biana, Joaquin, 2020a; Aguas, 2020).

The situation of education during a pandemic can be examined from two different perspectives. From one of them teaching can be placed alongside other spheres of social life. In comparison to trade, tourism, transport or gastronomy, the education system can appear to be stable and resistant to shock. After all, the pupils have the possibility of remote learning and the teachers don't lose their jobs - they can earn enough to support themselves and fulfil their mission. It is even possible to suppose that the pandemic has created additional possibilities for learning, particularly in the case of adult students, for whom home working or unemployment can be seen as gaining more free time and the possibility of taking on educational challenges as an answer to critical events (Woods, 1993).

A completely different picture of education appears when we look on it as a system which functions with the support of strictly defined education goals. In this case every change is dangerous, because it brings about the necessity of redefining teaching methods and checking their effectiveness in new conditions. In the case of the pandemic this must be done by trial and error, in real time. In such a situation the considered opinions of practitioners are unusually valuable, because they are able to supply science with knowledge from the front line, and because they are at the bottom of the hierarchy they have to grapple with the greatest problems on a daily basis $(\mathrm{Li}$, 2017).

The education of seniors has its own peculiarities (Ziebinska, 2010; Marcinkiewicz, Wilk, 2020). As with the education of adults generally, the motivation of the elderly is first and foremost based on strictly specified goals (Slowik-Krogulec, 2019). Seniors usually want to learn foreign languages so that they can communicate with grandchildren brought up in a different country, go travelling, or simply for social reasons, because learning then becomes a pretext for social gatherings where achievement has no special significance. Lockdown must be particularly onerous for this last group.

Remote learning was enforced by the emergency caused by the pandemic. It is difficult to identify it with online education, and the comparisons or attempts at identifying with e-learning must be considered as far from accurate. Remote learning is somewhat reminiscent of clumsy attempts at coping with an uncomfortable situation and attempts at obtaining the best possible results, despite worsening working conditions. Therefore, for those teachers who have so far only used the Internet to a small extent to support their teaching, remote learning can be a particularly serious challenge.

\section{Research aim}

The Aim of the research was the identification and characterization of changes in the organizational process of foreign language teaching caused by the pandemic. Attention was paid to the general problems connected with the adaption of the didactic process to remote learning, as well as to:

- the specific problems of remote education connected with seniors being the subject of the didactic process,

- the problems of remote learning connected with specifics of the subject being taught (foreign languages).

\section{Methods and materials}

The research was conducted in Poland, Georgia, Italy, Ukraine and Belarus at the end of 2020 and beginning of 2021.

Tools employed: A qualitative analysis of content was employed in the research. Research material was obtained with the aid of the intensified one-to-one interview 
technique. The statements of the educators became the unit of analysis. The initial categories embraced five areas of change connected with the pandemic:

- reorganization of the education institutions' activities

- the needs, expectations and behaviour of pupils, with particular regard to seniors

- the main problems connected with remote teaching

- changes in the area of education methods and content

- the specifics of teaching seniors foreign languages.

People researched: Educators specialized in teaching foreign languages $\mathrm{N}=18$ took part in the research (higher education students, academic teachers, lecturers working in language schools.)

\section{Results}

In planning the research process the initial categories were defined by taking the following into consideration - changes in the operation of an institute, changes in the needs of students (particularly seniors), problems connected with remote learning, and changes in the didactic process and adapting this process to the needs of seniors.

Reorganizing the operation of the institute

Changes in the reorganization of an institute depends on the type of institute and the country it is in. In all the countries researched, with the exception of Belarus, the schools were closed during the first wave of the pandemic and switched to remote learning. Non-formal institutes either generally suspended their operations or attempted to replace at least some of their lessons with remote learning.

On the basis of the statements made by foreign language teachers, it is possible to distinguish the following strategies:

1 - Suspension of operations through lack of clients (this concerns private language schools and Universities of the Third Age - R1 and R14)

2 - Changes in the method of teaching. Above all, this concerns the formal education system, but it also applies to societies and language schools which were conducting EU projects (in Poland R16 and in Italy R8.) Some language schools reduced group numbers and made some of their staff redundant (R13), and others switched to remote learning (R4).

3 - Limiting necessary changes as much as possible. The best example of this is Belarus, which did not announce a state of emergency due to the pandemic. Both teachers from Belarus declared that there were no significant changes in the U3A where they worked, apart from sanitary precautions (R5, R6)

This last strategy was reported only by the teachers in Belarus. By using the second strategy, institutes generally tried to do everything to survive in a difficult situation. The first strategy of operation was forced on language schools by the worsening financial situation of their clients, or by anxiety over health, particularly in the case of seniors. For this group, language learning ceased to be a priority.

\section{Changes in the needs, expectations and behaviour of students and seniors}

Three different types of student behaviour respond to the above-mentioned operational strategies - escape, combat, reinforcement.

Many students fell out of the system. In the case of formal and compulsory education, the reasons indicated were a lack of appropriate equipment, whereas in the case of seniors it was a lack of equipment, unfamiliarity with technology, or a lack of motivation towards remote learning because there was no possibility of interacting with other people.

Those students who decided on combatting the difficulties most often had to cope with lower motivation and apathy and, in the case of seniors, with depression, anxiety and anger. Some institutes (mostly NGOs) organized training for seniors in the use of

XLinguae, Volume 14 Issue 1, January 2021, ISSN 1337-8384, eISSN 2453-711X 
new technologies, thanks to which they were able to retain elderly students on their courses in Italy (R8) and in Poland (R16). Many pupils needed technical support during their lessons, and some took advantage of help from their parents. Younger students (pre-school and junior school) had problems with concentration (R2, R3, R7, $\mathrm{R} 10, \mathrm{R} 11)$.

For some pupils remote learning turned out to be better than what had formerly been offered. Gifted students did particularly well (R18). Seniors who with time became used to this kind of lesson, became more courageous and uninhibited in their on-line statements (R16). It turned out that the possibility of recording lessons was particularly useful, meaning that seniors could participate in lessons at a time convenient to them. Many of those who earlier had felt stressed during class lessons, maintained that mediated lessons actually had a therapeutic character (R16).

\section{The main problems connected with remote learning}

The majority of those interviewed indicated that it was the financial difficulties of adult students which ultimately decided on their resignation from the lessons.

In the case of people who participated in the classes, they repeat themselves: 1 - technical issues - sometimes the equipment fails, sometimes the internet connection

2 - lack of proper training for head teachers and teachers, who were left alone and struggled

to find solutions suitable for their institution

3 - emotional issues - triggered by isolation, fear and a feeling of insecurity

4 - specifics of remote teaching - most primary students don't treat it seriously

enough to

actually learn something

5 - cheating - especially when some parents or older siblings do the quizzes and tests, or answer the questions instead of the learners themselves - they care about marks instead of maintaining new skills.

\section{Changes in education methods and content}

Remote learning forced a change in the approach to teaching methods and set new priorities when it comes to the choice of educational content.

The application of education content in formal education revealed much underdeveloped material and errors in electronic textbooks (R3). In the case of adult students it became necessary to search for additional online materials more suitable for remote learning.

When it comes to teaching methods, it turned out that the biggest problem was a lack of direct contact. Generally, teachers see no possibility of working in groups or pairs. To some extent, these deficiencies were eliminated through work on the project and by using freely available material obtained from online publications.

Teachers attempted to strengthen motivation largely through the choice of more attractive content, either referring to the current situation of the pandemic (R7) or more interactive content, making use of games, quizzes and competitive elements (R3, R4), for example 'Kahoot'.

At the same time, teachers indicated that remote learning was more physically demanding, both for them and their pupils. Because of the necessity of searching for new teaching materials and testing new education methods, teachers had to devote much more time to preparing lessons (R7). On the other hand, after spending several hours (sometimes a dozen or more) in front of a screen, pupils showed symptoms of fatigue or even physical exhaustion (R16, R17). 
Material was frequently cut to a minimum, because in many cases it was not possible to achieve educational aims during lessons. For example, a topic which was formerly covered in one lesson had to be divided over two lessons (R14).

Particular problems were presented by having to explain new grammar issues, search for electronic worksheets published in open access, and shaping skills in speaking and listening comprehension, due to the limitations resulting from the specifics of indirect communication.

\section{The specifics of educating seniors in the area of foreign languages}

The pandemic has had a decidedly negative influence on the education of most seniors. The closure of institutes has forced them to stay at home and switch to remote learning. Unfortunately, seniors belong to the age group which has the least developed skills when it comes to using the latest technologies. From this, it should not be surprising that teachers point to this group as being the most aggrieved when it comes to the possibility of participating in language lessons. An exception to this were cases of the implementation of educational projects by non-governmental organizations, which turned out to be the most flexible in their operations and attempted to carry out their pre-planned lessons in one form or another. They invested additional time and resources in preparing their beneficiaries to switch to hybrid or remote mode by organizing additional lessons for them in suitable programs, such as for example Skype and Zoom (R8). Thanks to this, those who possessed a suitable connection and equipment, but lacked skills in using the new technologies, could quickly make up for their educational deficiencies.

Seniors who overcame the psychological barrier in using the new technologies quickly spotted new educational possibilities. One of the teachers interviewed (R16) pointed out that it was actually these seniors who, appearing in front of internet cameras, gained self-confidence and freedom of expression. Others also pointed out that the necessity of participating in remote learning caused some seniors to become more interested in the new technologies, and they studied the new possibilities of their computers and integrated peripheral devices, such as speakers, cameras, microphones, and headphones (R16).

It is also worth noting that some of the seniors excluded themselves from this new form of learning through fears for their own health or acquired medical conditions. The main reasons for resigning were problems with sight or hearing (R13). In the case of attempts to maintain stationary classes, seniors resigned because they felt threatened by their advanced age accompanied by lower immunological resistance, as well as by accompanying chronic diseases, which also placed them in the group of people at a particularly high risk of infection.

For many seniors, language learning ceased to be a priority in the hierarchy of their life goals. As indicated by one of the teachers interviewed, care for one's health became a fundamental value (R4). Decreased motivation among this age group resulted from the fact that remote language lessons no longer satisfied their need for affiliation. They also cast doubt on the sense of learning a language in a time when free travel was impossible (R4).

\section{Summary}

In analysing the problems connected with reorganizing the didactic process of language learning during a pandemic, preliminary categories have been combined and three key areas giving rise to problems defined:

- general problems connected with remote education

- problems connected with language education in its strictest sense

- problems connected with language education specific to seniors

XLinguae, Volume 14 Issue 1, January 2021, ISSN 1337-8384, eISSN 2453-711X 
The first group of education problems includes, above all, the non-specific ones which set the framework for remote education. They were selected and defined on the basis of an analysis of the answers to the first 3 questions in the interview handbook. They are:

- the specifics of mediated communication

- financial problems

- limited social contact

- technical problems

- emotional problems

Analysis of replies to questions 3 and 4 provided the material for selecting the specific problems of language education in the times of the pandemic. They are:

- changing or limiting educational content

- redefining educational aims

- changing the education method to a more attractive one based on interactivity

- attempting to cope with a lack of direct contact and the lowering of educational effectiveness which goes with it

- problems with teaching new grammar principles

Answers to the last question provided information on the subject of problems with seniors learning in the areas of:

- using the new technologies

- health

- controlling negative emotions connected with the pandemic itself

- a fall in general motivation and in particular motivation to language education

\section{Conclusions}

Remote learning creates new possibilities. One person interviewed in Georgia stated that in this form of education the main advantages can be seen as the saving of time, money and energy. Unfortunately only one teacher in Poland was of the same opinion. The remaining teachers saw only a host of problems connected with remote learning (Rotas, Cahapay, 2020).

An ambivalent approach to computer-mediated learning is most evident in statements regarding changes in education methodology. Some of the teachers saw problems, but on the other hand others saw a whole range of new perspectives and numerous possibilities of enriching their methodological workshops, especially when it comes to educational material and teaching methods (Ulum, 2020)

Furthermore, on the basis of an analysis of the material collected, it is possible to state that seniors have become a disadvantaged group, excluded from the field of education by the pandemic. The threat to health, combined with the relatively low digital skills of seniors, has led to some of them being completely eliminated from lessons. Those seniors who coped with technological challenges, just like some of the teachers, were generally able to discover new possibilities which they used to enhance the learning process. In this connection it could be expected that in the future the technological gap between those who use the new media and those who are excluded will widen. Faced with the possibility of a protracted pandemic, its subsequent recurrences or the spread of other dangerous viruses, bridging the technological gaps should be treated as a basic task for society.

Conclusions should also be drawn from the limitations which have affected us and do everything so as not to be surprised by a similar (very likely) situation in the future. Language education, enriched by the possibilities of using ad hoc solutions applied during a pandemic, may become more efficient and even more flexible. Perhaps it is also a sign to consider remote education as an alternative form to the existing 
traditional and stationary ones. Before the pandemic, institutions were closed to such opportunities. Now is a good time to think about this kind of problem.

\section{Bibliographic references}

AGUAS, J. J. S. 2020. Critical thinking in this time of global pandemic. In: Philosophia, vol. 21, n. 2, pp. 285-290. ISSN 2244-1875

BIANA, H. T. - JOAQUIN, J. J. B. 2020a. The ethics of scare: COVID-19 and the Philippines' fear appeals. In: Public Health, vol. 183, pp. 2-3. ISSN 0033-3506

BIANA, H. T. - JOAQUIN, J. J. B. 2020b. COVID-19: The need to heed distress calls of healthcare workers, In Journal of Public Health, UK, vol. 42, n. 4, pp. 853854. ISSN 1741-3842

BIANCO, R. - COBO, M. O. 2019a. Formal and informal language acquisition during the migration processes: A comparison between immigrants and refugees.. In: Lengua y Habla, vol. 23, pp. 399-412. ISSN 1316-1180.

BIANCO, R. - COBO, M. O. 2019b.The linguistic integration of refugees in Italy. In: Social Sciences, vol. 8, n. 10, 284 p. ISSN 2076-076.

BIANCO, R. - COBO, M. O. 2019c. Refugees education: an ethnography of teaching experiences in Jordan. In: The European Proceedings of Social and Behavioural Sciences, vol. 60, pp. 31-38. ISSN 2357-1330

COSKUN, H. 2020. Design of the Subject of Weather Report as a Course Unit in Language Teaching. In: Journal of Education Culture and Society. vol. 11, n.2, pp. 183-198. ISSN 2081-1640.

DANIEL, S. J. 2020. Education and the COVID-19 pandemic. In: Prospects. n. 49, pp. 91-96. ISSN 1573-9090.

GADUSOVA, Z. - HASKOVA, A. - SZARSOI, D. 2020. Teachers`competences evaluation: Case study. In: Science for Education Today, vol. 10, 3, pp. 164-177. ISSN 2658-6762.

FLORES, M.A. - SWENNEN, A. 2020. The COVID-19 pandemic and its effects on teacher education. In: European Journal of Teacher Education. vol 43, n. 3, pp.453456. ISSN 1469-5928.

HASKOVA, A. - MANDULAKOVA, S. - VAN MERODE. 2017. Problematic aspects of technology education in Slovakia. In: Communications - Scientific Letters of the University of Zilina, vol. 19, n. 1, pp. 75-80. ISSN 1335-4205.

HATAR, C. 2019. Social communication of seniors. In: XLinguae, vol. 12, n, 3, pp. 3-11. ISSN 2453-711X.

JOAQUIN, J. B. - BIANA, H. T. - DACELA, M. A. 2020. The Philippine Higher Education Sector in the Time of COVID-19. In: Frontiers in Education, vol. 5, 576371. ISSN 2504-284X

LI, L. 2017. Social Interaction and Teacher Cognition (Studies in Social Interaction). Edinburgh University Press. ISBN 978-0748675753.

MARCINKIEWICZ-WILK, A. 2020. Learning in late adulthood in the light of biographical research. In: Journal of Education Culture and Society. vol. 11, n. 2, pp. 133-146. ISSN 2081-1640.

MURGAS, F. - PETROVIC, F. 2020. Quality of life and quality of environment in Czechia in the period of the COVID-19 pandemic. In: Geograficky Casopis, vol. 72 n.2, pp. 261-274. ISSN 0016-7193.

ROTAS, E. E. - CAHAPAY, M. B. 2020. Difficulties in Remote Learning: Voices of Philippine University Students in the Wake of COVID-19 Crisis.In: Asian Journal of Distance Education. vol. 15, n. 2, pp. 147-158. ISSN 1347-9008.

XLinguae, Volume 14 Issue 1, January 2021, ISSN 1337-8384, eISSN 2453-711X 
SHALMA, I. - REKAI, K. 2020. Personal and Online Contact during the COVID-19 Pandemic among Nonresident Parents and their Children in Hungary. In: International Journal of Sociology. vol. 50, n. 2, pp. 1-9. ISSN 1557-9336.

SLOWIK-KROGULEC, A. 2019. Developing efficient foreign language classroom environment for older adult learners. vol. 10, n. 2, pp 189-200.ISSN 2081-1640.

ULUM, O. G. 2020. Pre-Service English Teachers' Narrative Identity. IN: Journal of Education Culture and Society. vol. 11, n. 1, pp. 92-101. ISSN 2081-1640.

WOODS, P. 1993. Critical Events in Education. In: British Journal of Sociology of Education. vol. 14, n. 4, pp. 355-371. ISSN 1465-3346.

ZIEBINSKA, B. 2010. Uniwersytety Trzeciego Wieku jako instytucje przeciwdzialajace marginalizacji osob starszych. Slask: Katowice. ISBN 978-837164-619-5.

Words: 3945

Characters: 25535 (14,19 standard pages)

Assistant Professor Aleksander Kobylarek, PhD

Institute of Pedagogy

University of Wroclaw

Dawida 1/3, 50-518 Wroclaw

Poland

aleksander.kobylarek@gmail.com

Associate Professor Emilia Alaverdov, PhD

Georgian Technical University

77, Kostava str., 0160, Tbilisi

Georgia

emily-78@mail.ru

Assistant Professor Luba Jakubowska, PhD

Department of Public Health Faculty of Health Sciences,

Wroclaw Medical University

Bartla 5, 51-618 Wroclaw

Poland

luba.jakubowska@umed.wroc.pl 